\title{
Mortality related to coagulase-negative staphylococcal bacteremia in febrile neutropenia: A cohort study
}

\author{
Regis G Rosa MD MSc, Rodrigo P dos Santos MD PhD, Luciano Z Goldani MD PhD
}

RG Rosa, RP dos Santos, LZ Goldani. Mortality related to coagulase-negative staphylococcal bacteremia in febrile neutropenia: A cohort study. Can J Infect Dis Med Microbiol 2014;25(1):e14-e17.

BACKGROUND: Coagulase-negative staphylococci (CoNS) are currently the most common isolates recovered from the blood of patients with cancer and febrile neutropenia (FN).

OBJECTIVES: To assess the mortality associated with bloodstream infections (BSIs) caused by CoNS in cancer patients with FN.

METHODS: A prospective cohort study was conducted in a single tertiary hospital from October 2009 to August 2011. Follow-ups were performed on all of the adult patients who were admitted to the hematology ward with cancer and FN. Bacteremia caused by CoNS was defined as two positive results of two independent cultures. Twentyeight days after the onset of FN, the mortality rates of the patients with BSIs caused by CoNS were compared with those of patients with BSIs caused by other pathogens.

RESULTS: A total of 169 subjects were evaluated. During the study period, 78 patients with BSIs were documented. Twenty-three BSIs (29.4\%) were a result of CoNS. CoNS-induced bacteremia resulted in lower 28-day mortality compared with bacteremia caused by other pathogens $(4.3 \%$ versus $32.7 \%$; log-rank $\mathrm{P}=0.009)$. In a Cox proportional hazards regression analysis, BSIs caused by CoNS were independently associated with lower mortality (HR 0.09 [95\% CI 0.01 to 0.74]).

CONCLUSIONS: In adult patients with cancer and FN, BSIs caused by CoNS were associated with lower mortality compared with BSIs caused by other pathogens.

Key Words: Bacteremia; Fever; Immunocompromised host; Mortality; Neutropenia; Staphylococcus

$\mathrm{C}$ oagulase-negative staphylococci (CoNS) are currently the most common isolates from the blood of patients with cancer and febrile neutropenia (FN) (1-3). Although bloodstream infections (BSIs) by CoNS are often considered to be indolent (4), their impact on the mortality of immunocompromised patients is not well established, particularly for patients with neutropenia secondary to cytotoxic chemotherapy.

Nosocomial isolates of CoNS tend to be multidrug resistant, and many are only susceptible to vancomycin $(5,6)$. In an era of increasing antibiotic resistance, determining the actual virulence of BSIs caused by CoNS in the context of FN is of paramount importance for the appropriate administration of vancomycin, particularly in centres in which the prevalence of methicillin-resistant Staphylococcus aureus is low. The aim of the present study was to evaluate the relevance of BSIs caused by CoNS in the mortality of adult patients with cancer and FN.

Study design and participants

\section{METHODS}

A prospective cohort study was conducted in the hematology ward of Hospital de Clínicas de Porto Alegre, Rio Grande do

\section{La mortalité liée à la bactériémie à staphylocoque à coagulase négative en cas de neutropénie fébrile : une étude de cohorte}

HISTORIQUE : Les staphylocoques à coagulase négative (SCoN) sont les isolats les plus prélevés dans le sang des patients atteints d'un cancer et d'une neutropénie fébrile (NF).

OBJECTIFS : Évaluer la mortalité associée aux infections sanguines (IS) causées par les SCoN chez des patients atteints du cancer ayant une NF.

MÉTHODOLOGIE : Les chercheurs ont mené une étude prospective de cohorte dans un seul hôpital de soins tertiaires entre octobre 2009 et août 2011. Ils ont assuré le suivi de tous les patients adultes atteints d'un cancer et d'une neutropénie fébrile qui avaient été hospitalisés à l'unité d'hématologie. Les bactériémies causées par les SCoN étaient définies comme deux résultats positifs dans deux cultures indépendantes. Vingt-huit jours après l'apparition de la NF, le taux de mortalité des patients atteints d'une IS causée par des SCoN était comparé à celui des patients ayant une IS causée par d'autres pathogènes.

RÉSULTATS : Au total, les chercheurs ont évalué 169 sujets. Pendant la période de l'étude, ils ont répertorié 78 patients ayant une IS. Vingttrois IS (29,4 \%) étaient causées par un SCoN. La bactériémie induite par un SCoN était responsable d'un taux de mortalité plus faible au bout de 28 jours que celle causée par d'autres pathogènes (4,3\% par rapport à 32,7 \%; test de Mantel Haenzel $\mathrm{P}=0,009)$. Dans une analyse de régression des hasards proportionnels de Cox, les IS causées par un SCoN étaient associées indépendamment à un taux de mortalité plus faible (rapport de risque 0,09 [95 \% IC 0,01 à 0,74]).

CONCLUSIONS : Chez des patients adultes atteints du cancer et de NF, les IS causées par un SCoN s'associaient à un taux de mortalité moins élevé que celles causées par d'autres pathogènes.

Sul, a teaching hospital and tertiary referral centre for bone marrow transplantation in southern Brazil. All consecutive subjects admitted between October 2009 and August 2011 were screened. Patients $\geq 18$ years of age with neutropenia (absolute neutrophil count $<500 \times 10^{9}$ cells $/ \mathrm{L}$ or $<1000 \times 10^{9}$ cells $/ \mathrm{L}$ with an expectation of decreasing to $<500 \times 10^{9}$ cells/L during the next $48 \mathrm{~h}$ ) and fever (a single axillary temperature measurement $\geq 38.5^{\circ} \mathrm{C}$ or temperature of $\geq 38.0^{\circ} \mathrm{C}$ sustained over a $1 \mathrm{~h}$ period) were eligible for the present study. Subjects who were only receiving palliative treatment, had an indication of outpatient treatment, and had neutropenia due to an etiology in addition to the manifestation of hematological malignancies or an adverse reaction to chemotherapy were excluded. Patients were not allowed to re-enter the study after a first episode of FN with documented BSI.

\section{Definitions}

Microbiological studies were performed at the onset of fever according to standards of practice and included two separate blood samples from two different sites. In the absence of an indwelling central venous catheter, the two blood sets were obtained from two distinct peripheral

Infectious Diseases Division and Infection Control Committee of Hospital de Clínicas de Porto Alegre; Universidade Federal do Rio Grande do Sul, Porto Alegre, Brazil

Correspondence: Dr Luciano Z Goldani, Infectious Diseases Unit, Hospital de Clínicas de Porto Alegre, Ramiro Barcelos 2350, Room 700,

Porto Alegre 90640-000, Brazil. Telephone 55-51-3359-8152, fax 55-51-3359-8152, e-mail lgoldani@ufrgs.br 


\section{TABLE 1 \\ Microorganisms isolated from 78 patients with febrile neutropenia and bloodstream infection}

\begin{tabular}{lc}
\hline Microorganism & $\mathbf{n}$ \\
\hline Coagulase-negative Staphylococcus species & 23 \\
Other pathogens* & \\
$\quad$ Escherichia coli & 27 \\
Pseudomonas aeruginosa & 9 \\
Klebsiella pneumoniae & 7 \\
Streptococcus species & 5 \\
Enterococcus faecalis & 4 \\
Enterobacter species & 2 \\
Serratia species & 2 \\
Candida species & 2 \\
Salmonella species & 1 \\
Staphylococcus aureus & 1 \\
Kocuria species & 1 \\
\hline
\end{tabular}

*There were six cases of polymicrobial bacteremia

veins. When an indwelling central venous catheter was present, one set of samples for blood culture was obtained through the indwelling central venous catheter and another set was collected from a peripheral vein. S aureus was identified using agar (blood agar and mannitol salt) via catalase and coagulase tests. CoNS were identified by Gram stain, the presence of catalase, bacitracin resistance and the absence of free coagulase. The susceptibilities of the isolated pathogens to antibiotics were evaluated according to the recommendations of the Clinical and Laboratory Standards Institute (7). Bacteremia caused by CoNS was defined as two positive results of two independent cultures. Bacteremia in one positive culture was considered diagnostic for other pathogens. Multidrug-resistant bacteremia was defined as a BSI that was a result of methicillin-resistant Staphylococcus or vancomycinresistant Enterococcus for Gram-positive bacteria, or resistance to $\geq 3$ classes of antimicrobial agents for Gram-negative bacteria. The Multinational Association for Supportive Care in Cancer (MASCC) Risk Index score was applied at the onset of fever to determine the risk for serious complications during FN (8); episodes were classified as high risk if the score was $<21$ points. Clinical comorbidity was defined as the presence of heart failure, diabetes mellitus, chronic pulmonary disease, chronic liver disease or chronic renal failure. Nosocomial FN was defined as the onset of FN after $48 \mathrm{~h}$ of hospitalization. Patients with FN were treated according to the 2002 guidelines of the Infectious Diseases Society of America (9). The initial antimicrobial treatment scheme was performed with $\beta$-lactam monotherapy with antipseudomonal activity; vancomycin was recommended as part of the initial empirical regimen only in cases with hemodynamic instability, suspected catheter-related infection, or infection of the skin and soft tissue. Antibiotic prophylaxis was not administered to patients.

\section{Outcome and follow-up}

The primary outcome of the study was mortality 28 days after the onset of FN. Patients were followed up through interviews and medical record review using a standardized data collection instrument by researchers who were not associated with the assistant physician's team. Follow-up was maintained for 28 days after fever began in neutropenic patients. Regarding patients who were discharged within 28 days, follow-up telephone calls were made on the 28th day after the onset of FN to determine whether they were still alive.

\section{Statistical analysis}

The $\chi^{2}$ and Fisher tests were used to compare categorical variables, and the Mann-Whitney $U$ test was used to compare continuous variables. Kaplan-Meier curves were used to calculate the time-dependent occurrence of death. The log-rank test was used for comparisons between groups. The multivariate Cox proportional hazards model was

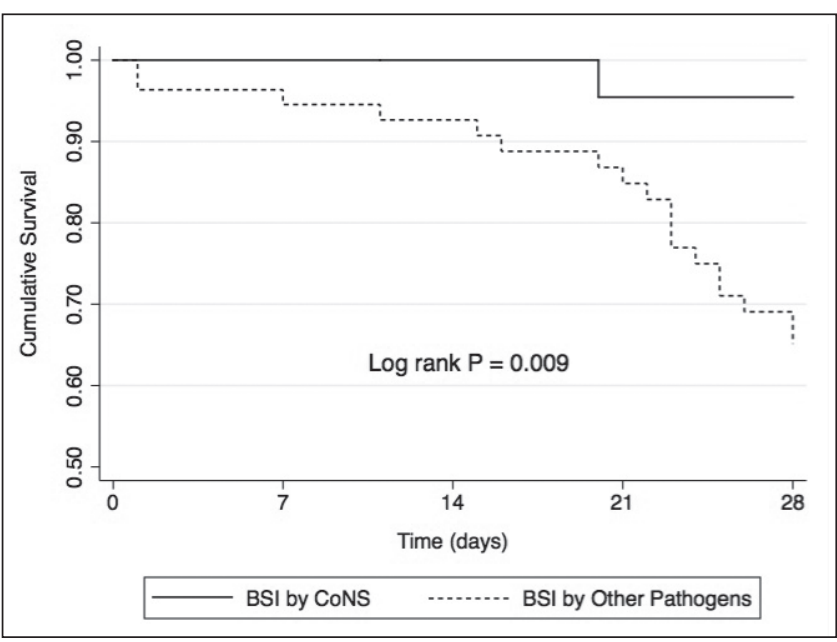

Figure 1) Survival curves of febrile neutropenic patients with bloodstream infection (BSI) caused by coagulase-negative Staphylococcus species (CoNS) and BSIs caused by other pathogens

used to assess mortality, and all variables with $\mathrm{P}<0.15$ in a univariate analysis were included. In the multivariate model, independent variables were eliminated from the highest to the lowest $\mathrm{P}$ value but remained in the model if $\mathrm{P}<0.05$. HRs were estimated along with $95 \%$ CIs. STATA version 12 (Stata Corp LP, USA) was used for statistical analysis.

\section{Ethics issues}

Written informed consent was obtained from all study participants. The institutional review board of Hospital de Clínicas de Porto Alegre (Porto Alegre, Brazil) approved the study.

\section{RESULTS}

A total of 169 patients were evaluated during the study period. During this time, 78 patients with BSIs were documented: $96.1 \%$ secondary to cytotoxic chemotherapy $(n=75)$ and $89.7 \%$ occurring after 48 h of hospitalization $(\mathrm{n}=70)$. Patients with hematological malignancies comprised $82 \%(n=64)$ of the study population. The proportion of patients who underwent high-dose chemotherapy (induction chemotherapy or hematopoietic stem cell transplantation) was $53.8 \%(n=42)$. The overall 28-day mortality associated with BSIs was $24.3 \%(n=19)$.

Of the total number of BSIs, 23 cases $(29.5 \%)$ were caused by CoNS, of which $65.2 \%(n=15)$ were due to methicillin-resistant isolates. Other pathogens accounted for $70.5 \%$ of all BSIs $(n=55)$, and the predominant microorganisms were Escherichia coli, Pseudomonas aeruginosa, Klebsiella pneumoniae and Streptococcus species (Table 1). The rate of BSIs caused by other multidrug-resistant pathogens was $18.1 \%(n=10)$, and the production of extended-spectrum $\beta$-lactamase was the most frequent type of antimicrobial resistance (80.0\%).

The characteristics of the groups of patients with BSIs caused by CoNS and BSIs caused by other pathogens are presented in Table 2 . Patients with BSIs caused by CoNS had a higher proportion of in vitro resistance of blood isolates to initial antibiotic treatment compared with patients with BSIs caused by other pathogens. There were no differences between the two study arms with respect to age, sex, presence of clinical comorbidity, type of cancer, relapsing underlying disease status, phase of chemotherapy, absolute neutrophil count at the time of diagnosis of FN, duration of neutropenia, proportion of nosocomial episodes of FN, presence of indwelling central venous catheter or MASCC score.

The 28-day mortality rate was significantly lower in the BSIs caused by CoNS group compared with with the BSIs caused by other pathogens group (4.3\% versus $32.7 \%$; log-rank $\mathrm{P}=0.009$ ) (Figure 1 ).

In the univariate Cox proportional hazards model, several characteristics were associated with 28-day mortality during FN (Table 3). 
TABLE 2

Comparison of characteristics of patients with bloodstream infection (BSI) caused by coagulase-negative Staphylococcus species (CoNS) and patients with BSI caused by other pathogens

\begin{tabular}{|c|c|c|c|}
\hline Characteristic & $\begin{array}{l}\text { BSIs caused by CoNS } \\
(n=23)\end{array}$ & $\begin{array}{l}\text { BSIs caused by other pathogens } \\
(n=55)\end{array}$ & $\mathbf{P}$ \\
\hline Age, years, mean \pm SD & $47.0 \pm 10.8$ & $41.4 \pm 15.0$ & 0.08 \\
\hline Female sex & $10(43.4)$ & $27(49.1)$ & 0.65 \\
\hline Type of cancer & & & $0.66^{*}$ \\
\hline Acute myeloid leukemia & $12(52.2)$ & $23(41.8)$ & \\
\hline Acute lymphoblastic leukemia & $3(13.0)$ & $9(16.4)$ & \\
\hline Multiple myeloma & $3(13.0)$ & $8(14.5)$ & \\
\hline Lymphoma & $4(17.4)$ & $6(10.9)$ & \\
\hline Other solid tumours & $0(0)$ & $4(7.3)$ & \\
\hline Relapsing underlying disease & $13(56.5)$ & $31(56.3)$ & 0.99 \\
\hline Phase of chemotherapy & & & $0.39^{*}$ \\
\hline Induction & $8(34.8)$ & $10(18.2)$ & \\
\hline Time to neutropenia recovery, days, median (IQR) & $16(17)$ & $9(11)$ & 0.20 \\
\hline Nosocomial episode of FN & $23(100)$ & $47(85.4)$ & 0.09 \\
\hline Presence of an indwelling central venous cateter & $22(95.6)$ & $44(80.0)$ & 0.09 \\
\hline High-risk MASCC score ${ }^{\dagger}$ & $8(34.7)$ & $21(38.1)$ & 0.77 \\
\hline In vitro resistance of blood isolates to initial antibiotic treatment & $15(65.2)$ & $14(25.4)$ & 0.001 \\
\hline
\end{tabular}

Data presented as $n(\%)$ unless otherwise indicated. ${ }^{*} \chi^{2}$ test for goodness of fit; ${ }^{\dagger}$ Multinational Association for Supportive Care in Cancer (MASCC) score <21 points. ANC Absolute neutrophil count; FN Febrile neutropenia; IQR Interquartile range (75th percentile - 25th percentile)

TABLE 3

Univariate analysis of risk factors for 28-day mortality in febrile neutropenic patients with bloodstream infection

\begin{tabular}{|c|c|c|c|c|}
\hline Variable & $\begin{array}{l}\text { Survival group } \\
\qquad(n=59)\end{array}$ & $\begin{array}{l}\text { Mortality group } \\
\qquad(n=19)\end{array}$ & $\mathrm{HR}(95 \% \mathrm{Cl})$ & $\mathbf{P}$ \\
\hline Age, years, mean \pm SD & $43.3 \pm 13.9$ & $42.2 \pm 14.9$ & $0.99(0.96-1.03)$ & 0.95 \\
\hline Female sex & $29(49.1)$ & $8(42.1)$ & $0.76(0.30-1.91)$ & 0.57 \\
\hline Clinical comorbidity & $14(23.7)$ & $6(31.5)$ & $1.39(0.53-3.66)$ & 0.50 \\
\hline Hematological neoplasm & $49(83.0)$ & $15(78.9)$ & $0.68(0.22-2.06)$ & 0.50 \\
\hline High-dose chemotherapy regimens* & $37(62.7)$ & $5(26.3)$ & $0.28(0.10-0.79)$ & 0.01 \\
\hline Relapsing underlying disease & $29(49.1)$ & $15(78.9)$ & $3.82(1.26-11.53)$ & 0.01 \\
\hline ANC at the time of diagnosis of $\mathrm{FN}, \times 10^{9} \mathrm{cells} / \mathrm{L}$, median (IQR) & $160(260)$ & $190(360)$ & $1.00(0.99-1.002)$ & 0.47 \\
\hline Time to neutropenia recovery, days, median (IQR) & $11(13)$ & $10(19)$ & $0.97(0.92-1.02)$ & 0.31 \\
\hline Nosocomial episode of FN & $55(93.2)$ & $15(78.9)$ & $0.36(0.12-1.10)$ & 0.07 \\
\hline High-risk MASCC score ${ }^{\dagger}$ & $19(32.2)$ & $10(52.6)$ & $2.31(0.94-5.70)$ & 0.06 \\
\hline In vitro resistance of blood isolates to initial antibiotic treatment & $21(35.5)$ & $8(42.1)$ & $1.10(0.44-2.73)$ & 0.83 \\
\hline Bloodstream infection by CoNS & $22(37.2)$ & $1(5.2)$ & $0.11(0.01-0.83)$ & 0.03 \\
\hline
\end{tabular}

Data presented as $n$ (\%) unless otherwise indicated. *Induction or hematopoietic stem cell transplantation; ${ }^{\dagger}$ Multinational Association for Supportive Care in Cancer (MASCC) score <21 points. ANC Absolute neutrophill count; CoNS Coagulase-negative Staphylococcus species; FN Febrile neutropenia; IQR Interquartile range (75th percentile - 25th percentile)

Patients who survived were more likely to have BSIs caused by CoNS $(\mathrm{P}=0.03)$ or to receive a regimen of high-dose chemotherapy $(\mathrm{P}=0.01)$. Presenting with relapsing disease stages $(\mathrm{P}=0.01)$ was significantly higher among nonsurvivors.

After the multivariate analysis (Table 4) was performed, the variables that constituted independent predictors for mortality were presentation with relapsing disease stages $(\mathrm{P}=0.008)$ and high-risk MASCC score $(\mathrm{P}=0.02)$. BSIs caused by CoNS were independently associated with higher survival rates $(\mathrm{P}=0.02)$. The assessment of whether mortality was attributable to infection was concordant in all 19 patients who died.

\section{DISCUSSION}

Despite a high incidence of methicillin resistance among CoNS isolates and the lack of vancomycin administration during routine initial
TABLE 4

Multivariate analysis of risk factors for 28-day mortality in febrile neutropenic patients with bloodstream infection

\begin{tabular}{lcl}
\hline Variable & Adjusted HR (95\% CI) & P \\
\hline High-risk MASCC score* & $2.84(1.14-7.06)$ & 0.02 \\
Relapsing underlying disease & $4.46(1.47-13.53)$ & 0.008 \\
Bloodstream infection by CoNS & $0.09(0.01-0.74)$ & 0.02 \\
\hline
\end{tabular}

*Multinational Association for Supportive Care in Cancer (MASCC) score $<21$ points. CoNS Coagulase-negative Staphylococcus species

antibiotic treatment, the present study revealed a lower 28-day mortality rate among cancer patients with FN and BSIs caused by CoNS compared with BSIs caused by other pathogens. 
The analysis of the characteristics of patients with FN showed a conservative bias with regard to the hypothesis of the lower virulence of BSIs caused by CoNS. Both the rate of multidrug-resistance and the in vitro resistance of blood isolates to the initial antibiotic administered were higher in the group of patients with BSIs caused by CoNS. Even so, bacteremia caused by CoNS was independently associated with higher survival rates.

Although some publications have demonstrated concern in relation to a trend of increasing methicillin resistance among CoNS isolates in FN $(10,11)$, our study suggests a low virulence of CoNS, even in the context of a high prevalence of methicillin resistance and the omission of a glycopeptide from the initial empirical antimicrobial treatment. These findings are comparable with previous studies that demonstrated a relatively benign clinical course of CoNS infections related to central venous catheter infection in bone marrow transplantation recipients (12) and a lack of increase in mortality attributable to CoNS bacteremia in noncritical patients (13). Moreover, our study results may provide a possible explanation for why randomized trials did not demonstrate a significant impact on mortality with the empirical association of glycopeptides in the initial treatment for FN (14) because CoNS represents the majority of Gram-positive isolates in FN (1-3).

There were limitations to the present study. Neither the initiation time of antibiotic therapy nor antimicrobial modifications during the

\section{REFERENCES}

1. Coullioud D, Van der Auwera P, Viot M, Lasset C. Prospective multicentric study of the etiology of 1051 bacteremic episodes in 782 cancer patients. CEMIC (French-Belgian Study Club of Infectious Diseases in Cancer). Support Care Cancer 1993;1:34-46.

2. Wisplinghoff H, Seifert H, Wenzel RP, Edmond MB. Current trends in the epidemiology of nosocomial bloodstream infections in patients with hematological malignancies and solid neoplasms in hospitals in the United States. Clin Infect Dis 2003;36:1103-10.

3. Ramphal R. Changes in the etiology of bacteremia in febrile neutropenic patients and the susceptibilities of the currently isolated pathogens. Clin Infect Dis 2004;39(Suppl 1):S25-31.

4. Rupp ME, Archer GL. Coagulase-negative staphylococci: Pathogens associated with medical progress. Clin Infect Dis 1994;19:231-43.

5. Jones R. Contemporary antimicrobial susceptibility patterns of bacterial pathogens commonly associated with febrile patients with neutropenia. Clin Infect Dis 1999;29:495-502.

6. Poyart C, Morand P, Buzyn A. [Etiology of bacterial infections in febrile neutropenic patients: The role of the laboratory in the diagnosis]. Presse Med 2004;33:460-6.

7. Clinical and Laboratory Standards Institute (CLSI) Performance Standards for Antimicrobial Susceptibility Testing: Twenty-second Informational Supplement. M100-S22. Wayne: Clinical and Laboratory Standards Institute, 2012.

8. Klastersky J, Paesmans M, Rubenstein EB, et al. The Multinational Association for Supportive Care in Cancer risk index: course of FN was controlled. Furthermore, the present study was susceptible to biases inherent to observational studies (selection, assessment and confounding); however, the appropriate measurement of variables and outcomes with previously defined objective criteria, the use of standardized data collection, follow-up by a research team that was not related to care and multivariate analysis minimized the possibility of systematic errors.

Future studies are required to assess markers of virulence of BSIs caused by CoNS in patients with FN and to determine which patients would benefit from treatment with glycopeptides.

The appropriate use of vancomycin in patients with FN and BSIs caused by CoNS could be an important strategy to avoid the horizontal spread of antibiotic resistance genes to more virulent bacteria such as $S$ aureus.

ACKNOWLEDGEMENTS: The authors thank all patients and the data collection team involved in this trial. The authors also thank the Hospital de Clínicas de Porto Alegre, particularly the hematology division and the Infection Control Committee, for their support in conducting the study.

DISCLOSURES: The authors have no conflicts of interest to declare.

FUNDING: No financial support was provided for this study.

A multinational scoring system for identifying low-risk febrile neutropenic cancer patients. J Clin Oncol 2000;18:3038-51.

9. Hughes WT, Armstrong D, Bodey GP, et al. 2002 guidelines for the use of antimicrobial agents in neutropenic patients with cancer. Clin Infect Dis 2002:34:730-51.

10. Butt T, Afzal RK, Ahmad RN, Salman M, Mahmood A, Anwar M. Bloodstream infections in febrile neutropenic patients: Bacterial spectrum and antimicrobial susceptibility pattern.

J Ayub Med Coll Abbottabad 2004;16:18-22.

11. Rolston K. Challenges in the treatment of infections caused by Gram-positive and Gram-negative bacteria in patients with cancer and neutropenia. Clin Infect Dis 2005;40:S246-52.

12. Engelhard D, Elishoov H, Strauss N, et al. Nosocomial coagulasenegative staphylococcal infections in bone marrow transplantation recipients with central vein catheter. A 5-year prospective study. Transplantation 1996;61:430-4.

13. Molina J, Peñuela I, Lepe JA, et al. Mortality and hospital stay related to coagulase-negative Staphylococci bacteremia in noncritical patients. J Infect 2013;66:155-62.

14. Paul M, Borok S, Fraser A, Vidal L, Leibovici, L. Empirical antibiotics against gram-positive infections for febrile neutropenia: Systematic review and meta-analysis of randomized controlled trials. J Antimicrob Chemother 2005;55:436-44. 


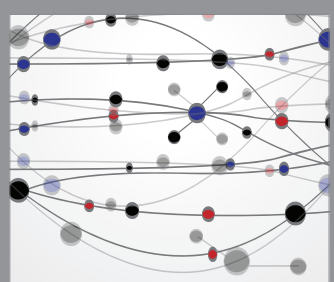

The Scientific World Journal
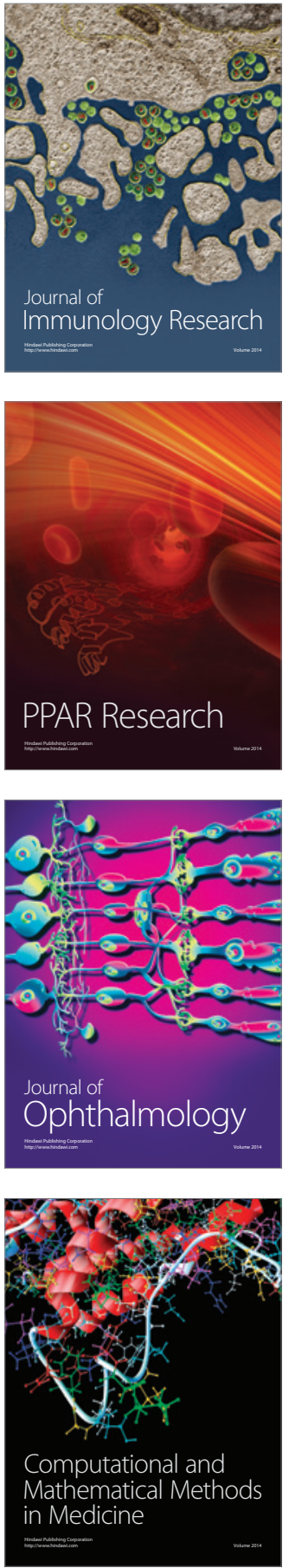

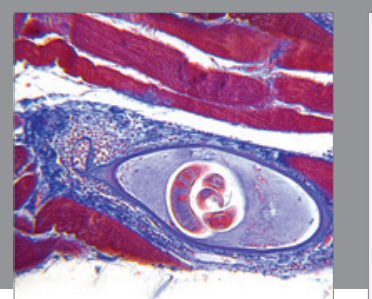

Gastroenterology Research and Practice

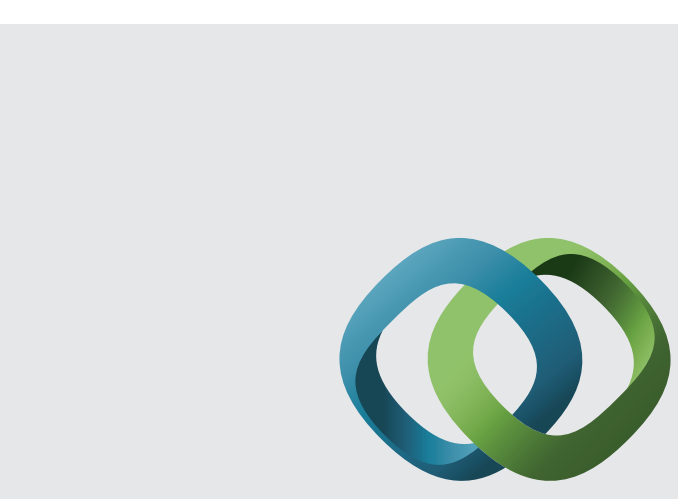

\section{Hindawi}

Submit your manuscripts at

http://www.hindawi.com
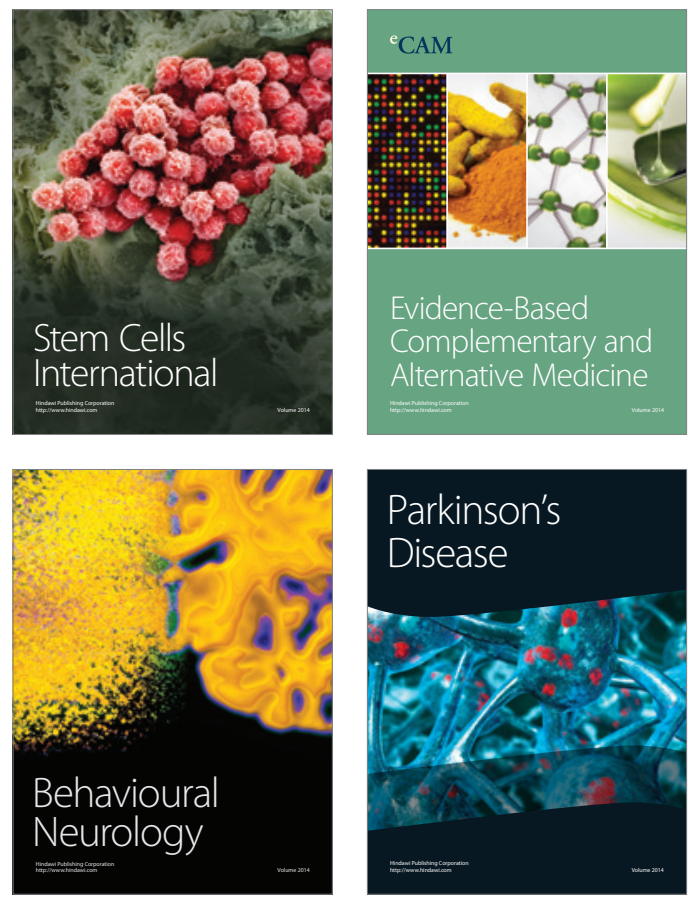
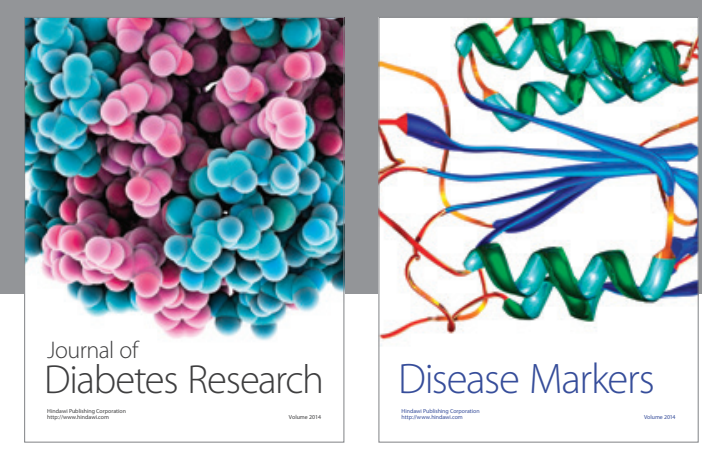

Disease Markers
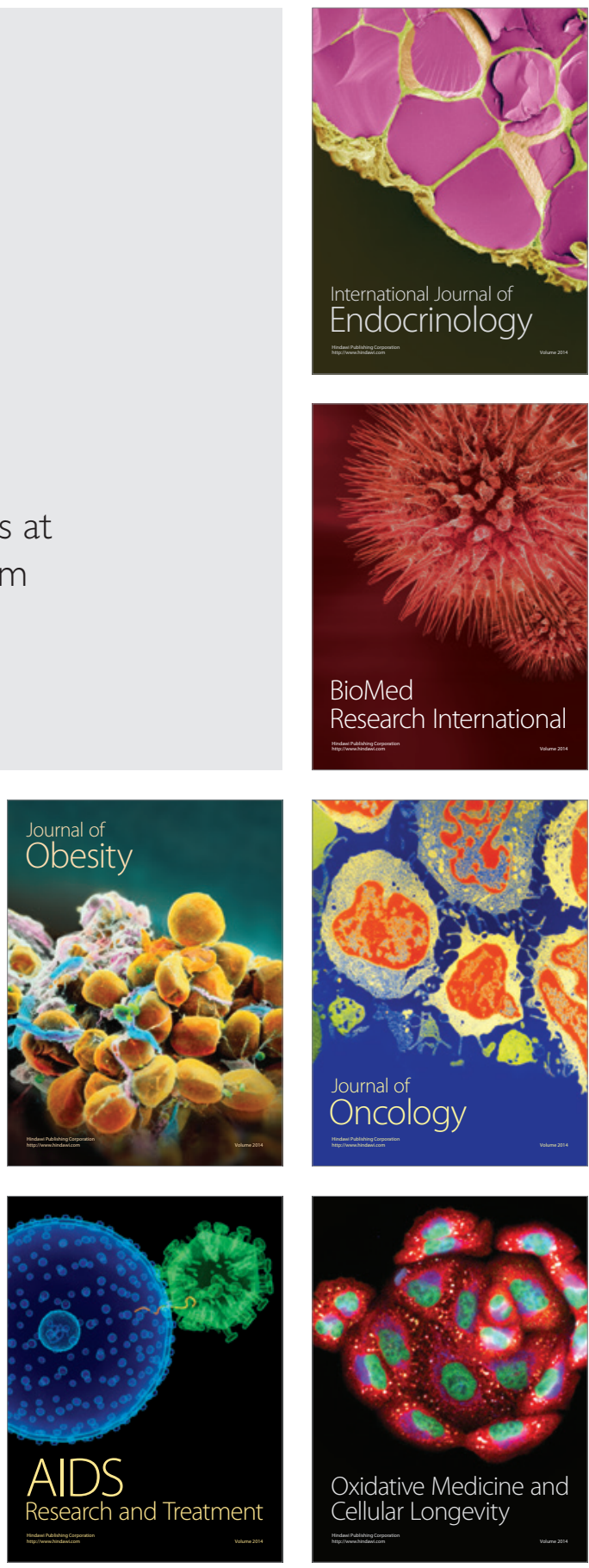